Understanding the unique contributions of home numeracy, inhibitory control, the approximate number system, and spontaneous focusing on number for children's math abilities

by

Alex Marissa Silver

B.A., Johns Hopkins University, 2014

Submitted to the Graduate Faculty of the

Dietrich School of Arts and Sciences in partial fulfillment

of the requirements for the degree of

Master of Science

University of Pittsburgh 


\section{UNIVERSITY OF PITTSBURGH}

\section{DIETRICH SCHOOL OF ARTS AND SCIENCES}

This thesis was presented

by

\section{Alex Marissa Silver}

It was defended on

December 4, 2020

and approved by

Timothy Nokes-Malach, Associate Professor, Department of Psychology Elizabeth Votruba-Drzal, Professor, Department of Psychology

Thesis Advisor: Melissa E. Libertus, Associate Professor, Department of Psychology 
Copyright (C) by Alex Marissa Silver 


\title{
Understanding the unique contributions of home numeracy, inhibitory control, the approximate number system, and spontaneous focusing on number for children's math abilities
}

\author{
Alex Marissa Silver, MS \\ University of Pittsburgh, 2021
}

Math abilities predict children's academic achievement and outcomes in adulthood such as full-time employment and income. Previous work indicates that parenting factors (i.e., education, parent math ability, frequency of math activities) relate to children's math performance. Further, research demonstrates that both domain-general (i.e., language skills, inhibitory control) and domain-specific (i.e., approximate number system acuity, spontaneous focusing on number) cognitive predictors are related to math during early childhood. However, no work has examined all of these factors together to identify their unique contributions for early math. Here, we examine whether parent-level and child-level factors uniquely explain children's math abilities. To this end, 112 four-year-old children and one of their parents completed a battery of assessments and questionnaires. Results indicate that children's math performance is uniquely predicted by the frequency of home math activities, as well as children's own inhibitory control, approximate number system acuity, and tendency to spontaneously focus on number. 
Table of contents

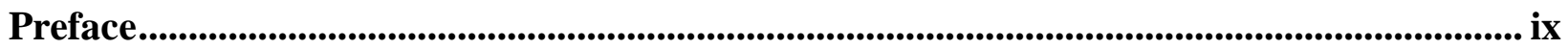

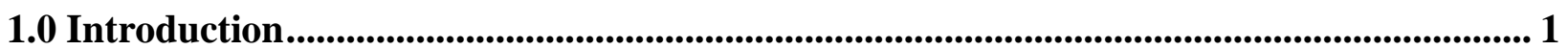

1.1 Parent-level predictors of children's math performance.............................................. 2

1.2 Child-level predictors of children's math performance..........................................4

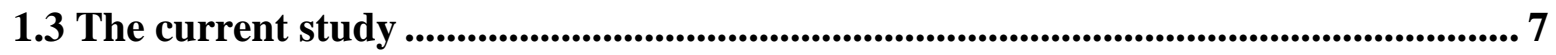

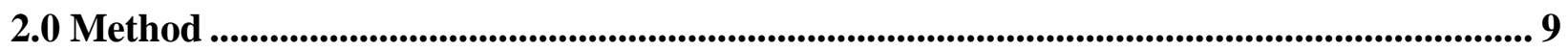

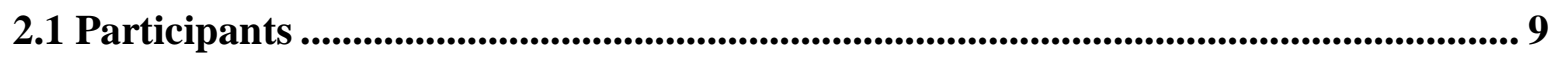

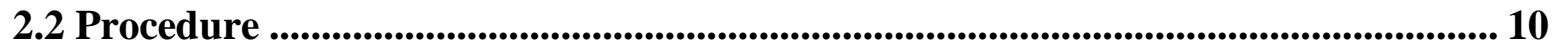

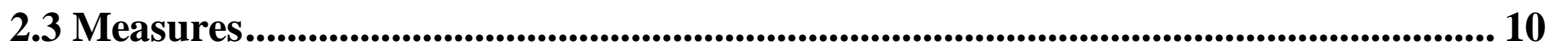

2.3.1 Parent's standardized math performance ..................................................10

2.3.2 Parent's frequency of home math activities...............................................11

2.3.3 Demographic information .......................................................................................11

2.3.4 Child's expressive vocabulary ..............................................................................12

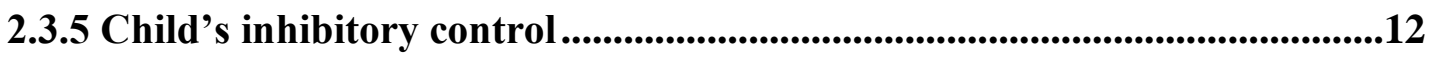

2.3.6 Child's approximate number system acuity ....................................................13

2.3.7 Child's spontaneous focusing on numerosity tendency ..............................14

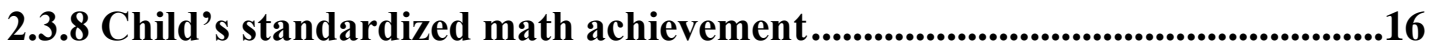

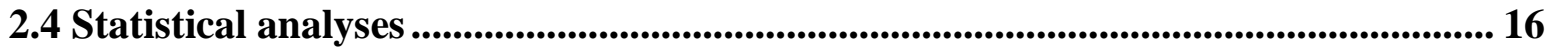

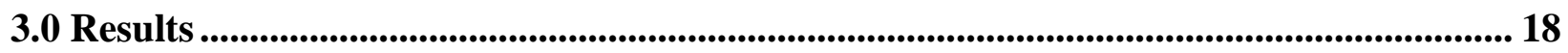

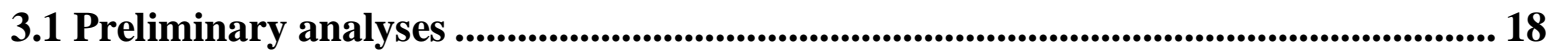

3.2 Parent predictors of children's math abilities ..................................................... 21 
3.3 Child predictors of children's math abilities ....................................................... 21

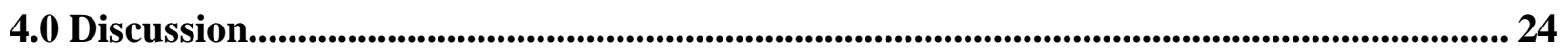

4.1 Parent-level predictors of children's math performance....................................... 24

4.2 Child-level predictors of children's math performance................................................ 26

4.3 Limitations, conclusions, and future directions ........................................................ 28

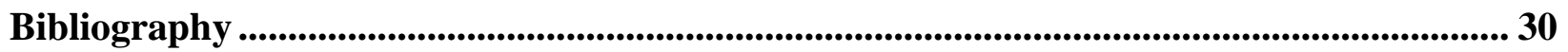




\section{List of tables}

Table 1 Descriptive statistics and correlations for key study variables, $\mathrm{N}=112$................. 20

Table 2 Parent and child factors as predictors of children's math ability ........................... 23 


\section{List of figures}

Figure 1 Parent- and child-level predictors of children's math performance......................... 2 


\section{Preface}

Thank you to my committee members, co-authors, and lab mates for their feedback, advice, help, and support with this project. None of this would be possible without the determined efforts and wonderful advice of my advisor, Melissa. I send my greatest appreciation to the families who participated in this research. Finally, particular thanks to my family for their never-ending moral support and confidence in me, especially my parents for their unwavering commitment to seeing me achieve my goals, and my husband for his boundless faith in me. 


\subsection{Introduction}

Every day brings opportunities for children and adults to use math: from measuring the correct quantity of ingredients when following a recipe to calculating the time it will take to arrive at an appointment on time, numerical information is critical. Nonetheless, many adults struggle to perform simple calculations. Individual differences in math skills are related to other important outcomes, including educational attainment, career choice and likelihood of full-time employment, income, financial and health decision making, and health outcomes (Agarwal \& Mazumder, 2013; Currie \& Thomas, 1999; Reyna \& Brainerd, 2007; Trusty et al., 2000). These individual differences are present early: already by the time of entry to kindergarten, there is large variability in math performance (Jordan et al., 2009).

Given the importance of math achievement for such wide-ranging life outcomes, much work has examined possible predictors of individual differences in young children's math abilities. Past work addressing sources of this heterogeneity typically either examined how children's experiences at home with their parents may foster math skills or focused on how children's underlying cognitive skills support their math learning. In this study, we examine how parent-level and child-level factors independently predict preschool-aged children's math achievement in order to identify the character- istics that uniquely relate to math learning. Specifically, we identify several factors that have been studied in relative isolation in past work, including socioeconomic status, parents' own math abilities, children's opportunities to learn math through home math activities with their parents, and a range of children's cognitive skills (see Figure 1). Importantly, we will consider both children's domain-general cognitive skills (i.e., language skills, inhibitory 
control) as well as their domain-specific cognitive skills (i.e., approximate number system acuity, and tendency to spontaneously focus on number).

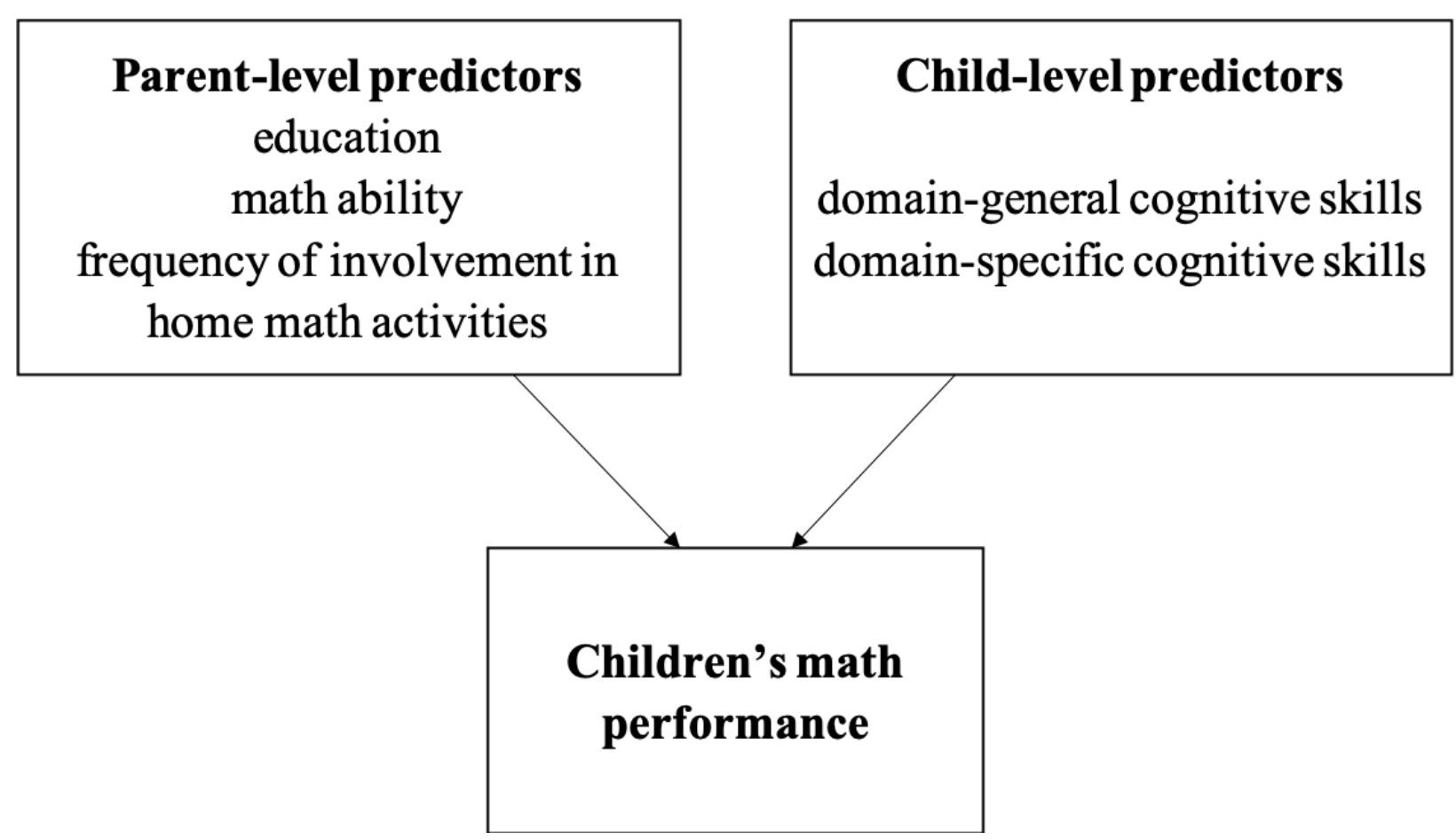

Figure 1 Parent- and child-level predictors of children's math performance

\subsection{Parent-level predictors of children's math performance}

Much work has identified that children's early math skills are related to social and environmental factors (LeFevre et al., 2009; Levine et al., 2010). This is particularly salient in the case of parents, who are often the primary introduction to math for children before they begin formal schooling. In the United States, children of parents with high socioeconomic status (SES), including higher levels of education or income, tend to outperform their low-SES peers in math 
(Davis-Kean, 2005; see Jordan \& Levine, 2009, for a review). These SES differences in math achievement are comparable in magnitude to those seen in reading and language skills (see Duncan \& Magnuson, 2011, for a review) and may be attributable to increased resources, including financial and psychological resources as well as time, that can be invested in children (Duncan et al., 2014; Foster, 2002).

Children's math skills are also related to parents' own math abilities, as evidenced through studies using intergenerational correlational designs (Braham \& Libertus, 2017). Some evidence suggests this may be due to shared genetics, as past work has identified that math abilities are highly heritable (Hart et al., 2009). However, it is also likely that parents with higher math abilities create environments for their children that are more stimulating or supportive of math. Therefore, it may not be the genetic predisposition for math achievement, but the environmental parenting factors that explain intergenerational associations between children's and parents' math performance. Some previous work suggests that this is likely the case: Crane (1996) found that the effect of parents' cognitive abilities on children's math performance was substantially reduced when measures of the home numeracy environment were included in analyses. This suggests that although parents may pass on genetic predispositions for high math achievement, their role in shaping the environmental factors around a child may play a larger part in children's math performance.

Indeed, many studies indicate that children benefit from exposure to math content at home. The frequency of home numeracy activities is typically positively correlated with children's math skills (Blevins-Knabe \& Musun-Miller, 1996; Huntsinger et al., 2016; LeFevre et al., 2009; Mutaf Yildiz et al., 2018). Although there is some debate regarding how to measure math activities in the home and which types of activities are most strongly predictive of children's outcomes (see Elliott 
\& Bachman, 2018, for a review), most past work suggests that parents who engage in more frequent and varied math activities with their preschool-aged children have children who tend to perform better in math.

When considering parents' SES, math skills, and math activities, it is important to recognize the potential for interrelations between them. Attaining higher levels of education likely offers parents more opportunities to develop and practice using advanced math skills. Furthermore, both parental SES and math ability may relate to parents' provision of math activities in the home. Parents with higher SES may have more time or resources available to devote to learning activities at home (Duncan et al., 2014; Foster, 2002). Additionally, it stands to reason that parents with more advanced math skills may be more likely to engage in math activities at home if they are more comfortable generating ideas for activities that involve math or implementing these ideas. In an attempt to consider the relative contributions of these parenting factors on children's math achievement, we include measures of parent education, parent math ability, and frequency of home math activities in the current study.

\subsection{Child-level predictors of children's math performance}

Similar to parent-level predictors of children's math achievement, much work has attempted to identify child-level cognitive factors associated with math performance. Studies examining child- level factors have identified both domain-general and domain-specific cognitive abilities that relate to children's math performance. Domain-general abilities including language skills are related to children's math performance (Purpura et al., 2011). Specifically, Purpura et al. (2011) found that stronger print knowledge and vocabulary skills are associated with better math 
performance in three- to five- year-old children, above and beyond numeracy skills and nonverbal cognitive abilities. In addition, executive functioning has long been argued to predict children's math achievement. Inhibitory control, in particular, is a consistent predictor of preschool-aged children's math performance (see Allan et al., 2014, for a review; Aunio et al., 2004; Clark et al., 2010; Fuhs \& McNeil, 2013). Children who possess stronger inhibition and are better able to stop or prevent prepotent responses tend to perform better in math. Thus, here we will include both vocabulary knowledge and inhibitory control as domain-general predictors of early math performance.

In addition to domain-general cognitive factors, domain-specific cognitive factors are also related to children's math achievement. For example, the acuity of the approximate number system (ANS) has been linked to math performance. The ANS allows for imprecise estimations of large quantities and is present from birth (Coubart et al., 2014; Dehaene, 1997; Libertus \& Brannon, 2009). Although the ANS is present in all humans, individual differences in ANS acuity exist. Infants' ANS acuity at 6 months of age is related to their math performance 3 years later (Starr et al., 2013), and preschoolers' performance in ANS tasks is related to their later school math performance (Bonny \& Lourenco, 2013; Libertus et al., 2013b, 2013a; Mazzocco et al., 2011). The relation between the ANS and math ability typically holds even when controlling for domaingeneral cognitive skills such as inhibitory control, working memory, attention, general intelligence, and verbal skills (Bonny \& Lourenco, 2013; Libertus et al., 2013b, 2013a; Keller \& Libertus, 2015; Mazzocco et al., 2011). However, a number of studies have failed to replicate the direct link between the ANS and math and argue that these observed associations are attributable to other cognitive factors (Fuhs \& McNeil, 2013; Gilmore et al., 2013; De Smedt \& Gilmore, 2011; Soltész et al., 2010), resulting in a lively debate regarding the nature of the ANS (Dietrich et al., 
2015; Gebuis et al., 2016; Gilmore et al., 2011; Leibovich \& Ansari, 2016; Leibovich et al., 2017). Here, we will examine how children's ANS acuity is related to their math achievement, even when controlling for other domain-specific, domain-general and environmental factors.

Another domain-specific characteristic of children that has been linked to math ability is their spontaneous focusing on numerosity (SFON). SFON measures a child's tendency to attend to and utilize numerical information without being prompted, such as by counting sets of objects in their environment (e.g., counting the number of apples in a bowl). This term was coined by Hannula and Lehtinen (2005) to describe a child's ability to selectively attend to number without explicit instruction or prompting to do so. Prior work has found significant individual differences in children's tendency to spontaneously focus on number, and these differences are associated with differences in children's performance on other math tasks (Gray \& Reeve, 2016; Hannula \& Lehtinen, 2005; Hannula et al., 2010; Hannula-Sormunen et al., 2015; Lepola \& HannulaSormunen, 2019; McMullen et al., 2015; Nanu et al., 2018). Children's SFON scores at age 5 predict their later math performance at age 12 years (Hannula-Sormunen et al., 2015; McMullen et al., 2015), and similar links have been found between preschool-aged children's SFON and their math scores at the end of elementary school (Nanu et al., 2018). These relations appear to be domain-specific, as SFON performance predicts children's math but not their reading performance (Hannula et al., 2010; Hannula-Sormunen et al., 2015; Nanu et al., 2018). Although the specific mechanisms underlying these associations have yet to be uncovered, some work indicates that focusing on number may be particularly helpful for understanding the mapping between symbolic and non-symbolic representations of number (Batchelor et al., 2015). Additionally, SFON performance is associated with children's other cognitive abilities, including ANS acuity and response inhibition (Fuhs et al., 2018). 
Much debate has surrounded the roles of these domain-specific cognitive skills and whether they are uniquely linked with math performance. In particular, some researchers have argued that the link between the ANS and math performance can be explained by inhibitory control (Fuhs \& McNeil, 2013; Gilmore et al., 2013), whereas other work has found that ANS acuity and inhibition remain unique, independent predictors of children's math performance (Keller \& Libertus, 2015). Similarly, it has been argued that the relations found between the ANS and math

performance may be explained by SFON (Fuhs et al., 2018). Few studies have examined all of these cognitive skills together, and no work to date has attempted to parse out the unique contributions of these distinct child factors in conjunction with other critical individual and parental factors on children's math performance.

\subsection{The current study}

The extant literature examining predictors of children's math performance has primarily focused either on parent-level factors or on child-level factors (both domain-general and domainspecific ones), without much examination of how these parent and child factors may overlap. In this study, we examine the extent to which parent factors and children's underlying cognitive skills, including both domain-general and domain-specific skills, uniquely predict children's early math achievement. Specifically, we first replicate the relations between these factors and children's math abilities, and then examine whether parent- and child-level factors contribute uniquely to predict children's math ability, even when controlling for the others. Using hierarchical linear regression, we first examine the relations between distal factors (i.e., parenting and demographic factors) and children's math achievement, and then add in the more proximal, child- 
level factors (i.e., expressive vocabulary, inhibitory control, ANS acuity, SFON tendency) to determine whether any of these factors remain uniquely predictive of children's math achievement when controlling for the others. Based on some past research that has identified both parent and child factors as significant predictors of math achievement in studies including measures of children's prior math achievement (e.g., Huntsinger et al., 2016; Jordan et al., 2009), we hypothesize that parental education, parental math skills, home math activities, and children's domain-specific and domain-general cognitive skills will each uniquely relate to children's math achievement. 


\subsection{Method}

\subsection{Participants}

Participants were 112 preschool-aged children (55 boys) and one of their parents. Participants were part of a larger longitudinal study, where sample size was determined by the larger goals of the longitudinal study. Children in this study ranged in age from 3 years 11 months

to 4 years 4 months $(M=4$ years 1 month) and were primarily White, non-Hispanic $(82 \%)$. Most parents participating in this study were mothers (95\%), and $90 \%$ of parents had at least a Bachelor's degree. Of the remaining $10 \%$, four parents reported their highest degree as a high school diploma or equivalent, two completed a vocational or technical program after high school, four completed some college credits, and three completed an Associates' degree. An additional 30 children (18 boys) and their parents participated but were dropped from analyses due to incomplete or missing data. Families were recruited from a mid-sized city in the United States through a combination of flyers, online postings, and mailings, and were compensated 8 USD per hour for their time. Prior to any data collection, parents provided written informed consent as approved by the local Institutional Review Board. Parents were not told that this was a study about early math, however some families had participated in previous studies in the lab and may have been aware of the focus of the research. 


\subsection{Procedure}

Parents and children came into the laboratory as part of a larger longitudinal study; data for the analyses presented in the current paper were collected during families' second visit to the lab. During this visit, parents and children completed a variety of tasks independently: Children completed two measures of SFON, followed by a standardized math assessment, a non-symbolic number comparison task, and a measure of inhibitory control, while parents completed numerous surveys as well as standardized math assessments.

In addition to the measures described in detail below, parents and children completed a 10minute free play interaction when they first arrived in the lab and children completed a preferential looking paradigm to measure children's non-symbolic number discrimination abilities. Both of these activities occurred prior to the completion of all of the measures described below but are not of interest to the current study. Parents completed measures of language and reading skills as well as non-symbolic math ability that were also not used in the present study.

\subsection{Measures}

\subsubsection{Parent's standardized math performance}

Parental math performance was assessed using the Woodcock-Johnson Tests of Achievement III (WJ- III; Woodcock et al., 2001). Parents completed the Math Calculation subtest, which is untimed and asked them to solve as many problems as they could, including arithmetic, algebra and calculus. Then parents completed the Math Fluency subtest, a timed test of math 
fluency where they were given simple arithmetic problems and instructed to complete as many problems as they could in three minutes. Parents' scores on the Math Calculation and Math Fluency subtests were then used to compute a normed Math Calculation Skills Composite Score. The WJIII is a standardized measure of achievement, with the Math Calculation Skills Composite Score showing excellent reliability with Cronbach's alpha of 0.94 (Woodcock et al., 2001).

\subsubsection{Parent's frequency of home math activities}

Parents completed the frequency of home activities questionnaire by LeFevre et al. (2009). Parents were asked to indicate how often in the past month they had participated in listed activities (e.g., "Identifying names of written numbers") with their child on a scale from 0 ("Did not occur") to 4 (“Almost daily”), and their responses for all math-related items were averaged to create a total frequency of math activities score. This scale has acceptable internal reliability, with Cronbach's alpha of 0.80 .

\subsubsection{Demographic information}

Parents reported demographic information about themselves and their child. Parents reported gender identity as well as birth dates for themselves and their child which were used to calculate age. Finally, parents reported their highest level of education attained. Parent education was dummy coded into two groups: parents with less than a college degree, and parents who had earned a college degree or graduate degree. 


\subsubsection{Child's expressive vocabulary}

To ensure that the measures of children's math achievement reflected math ability specifically, and not simply children's cognitive abilities in general, we included a measure of children's expressive vocabulary. Children's vocabulary was assessed using the Developmental Vocabulary Assessment for Parents, a parent-report measure of children's language development (DVAP; Libertus et al., 2015). Parents were asked to read through a representative list of words and check off any words that they had heard their child say. Children's scores were calculated as the total number of words that parents reported their children to have used. This questionnaire has been validated as an alternative to a time-intensive, experimenter-administered test of vocabulary. The DVAP shows high concurrent validity and is highly correlated with other measures of children's vocabulary, including the Peabody Picture Vocabulary Test (with a coefficient of 0.69 ) and the MacArthur-Bates Communicative Development Inventories (with a coefficient of 0.79; Libertus et al., 2015).

\subsubsection{Child's inhibitory control}

Children's inhibitory control was assessed using a modified Day-Night Stroop task (Gerstadt et al., 1994). In this assessment, children were shown images and instructed to say "day" when shown one image, and "night" when shown another image. The incongruent task asked children to say "night" when shown a sun image, and "day" when shown a moon image, requiring children to inhibit their prepotent association response. The control task showed children images of either a checkerboard or a squiggle pattern and required children to form a new association between the images and the words, without requiring inhibition of a prepotent response. This 
control task requires the same formation of a new association between a word and picture as in the incongruent task but does not require inhibition. By including children's scores in the control task in models using the incongruent task, we can control for children's ability to form a new association and use this association to follow a rule in the incongruent task, such that performance on the incongruent task reflects only their ability to inhibit a prepotent response.

The order in which children were administered the incongruent and control tasks was counter- balanced across children. Children received 16 trials of the incongruent task and 16 trials of the control task, each of which had 8 trials of "day" and 8 trials of "night" correct responses. Children were not given any feedback after responding to a trial. In each trial, children could receive 0,1 or 2 points for their response. Children received 2 points for every response that was correct on the first try, and 1 point for an incorrect response that they fixed spontaneously. Children received 0 points for any incorrect responses. Children's scores for all incongruent task trials were averaged to create their incongruent task score, and their scores for all control task trials were averaged to create their control task score. Past work demonstrates that the Day-Night Stroop task is a reliable measure of young children's interference control that is highly correlated with other measures of inhibition, with correlation coefficients as high as 0.79 (Montgomery \& Koeltzow, 2010).

\subsubsection{Child's approximate number system acuity}

We used a non-symbolic number comparison task based on the Psychological Assessment of Numerical Ability (Panamath; Halberda et al., 2008) to measure children's acuity of the approximate number system (ANS). Children were briefly (i.e., $2500 \mathrm{~ms}$ ) shown yellow and blue dots on a touchscreen computer screen and were asked to judge whether there were more yellow 
or blue dots and indicate their response by tapping the side of the screen with the larger number. Presentation duration of the stimuli was too short for the children to count the numbers of dots to ensure that children relied on the approximate number system to solve the task. The side of the larger quantity was counter- balanced across trials. Children received 48 total trials with equal numbers of trials for each of four ratios $(1.3: 1,1.5: 1,2: 1$, or $3: 1)$ with a set size ranging from 5 to 21 dots per side. Perceptual cues to determine the correct response were controlled via use of three trial types. One-third of trials were Correlated (i.e., the side with the larger number also had the larger cumulative area), one-third of trials were Anti-Correlated (i.e., the side with the smaller number had the larger cumulative area but cumulative perimeter was equal) and one-third of trials were Neutral (i.e., the arrays had equal cumulative areas). Previous work has found SpearmanBrown corrected split-half reliability for children is 0.74 (Braham \& Libertus, 2017). An overall accuracy score for each child was used as the measure of ANS acuity.

\subsubsection{Child's spontaneous focusing on numerosity tendency}

Children completed two measures of SFON, the "model" task and the "puppet" task, adapted from Hannula and Lehtinen (2005). As in Hannula and Lehtinen (2005), for the "model" task, an experimenter stamped a quantity of spikes onto a picture of a dinosaur, flipped it over, and asked the child to do the same to an identical dinosaur picture. Children completed three trials, each with a different quantity of stamps required. Here, the experimenter stamped two blue triangles on the first dinosaur, then four red diamonds on the second dinosaur. On the third dinosaur she stamped two green squares and three green rhombuses. For the "puppet" task, as in Hannula and Lehtinen (2005), an experimenter fed quantities of marbles to a toy puppet and asked the child to repeat his or her actions. The experimenter and child each fed the puppet for three trials. Here, 
the experimenter fed two marbles to the puppet in the first trial, three marbles in the second trial, and one marble in the third trial. Both SFON tasks were video-recorded and later transcribed by trained research assistants.

Research assistants also coded the videos for verbal and non-verbal instances of children's tendency to spontaneously focus on number, following the criteria of Hannula and Lehtinen (2005). Specifically, children were coded as focusing on number through speech in a given trial if they mentioned number or quantity (e.g., "I'm going to feed him three," "I don't remember what you did but I want to put five stamps," or "How many did you do?"). Children were coded as focusing on number through action in a given trial if they replicated the number used by the experimenter (e.g., put exactly the same number of spikes on the dinosaur, fed the puppet the exact same number of marbles). For the first two trials of the "model" task, children were coded as focusing on number if they replicated exactly two triangles or exactly four diamonds. To allow for the most flexibility, for the third trial of the "model" task children were coded as focusing on number through action if they replicated the exact number of squares or the exact number of rhombuses, or the exact same total number of stamps regardless of which shapes they used. This coding system was used only for the final trial as this was the only case in which children were able to produce multiple sets and thus had multiple opportunities to attend to number (i.e., in the first two trials, there was only one set present). Separate SFON scores for each task were calculated as the total number of trials that the child spontaneously focused on number in either speech or action out of three total trials. A composite SFON tendency score was then created by summing the separate SFON scores, with possible total SFON tendency scores ranging from 0 to 6 . This composite SFON tendency score showed acceptable internal consistency, with Cronbach's alpha 
of 0.66 . Intercoder reliability in coding child speech was quite high, with two independent coders agreeing on $95 \%$ of the 384 double-coded trials of the SFON tasks.

\subsubsection{Child's standardized math achievement}

Children completed the Test of Early Mathematics Ability, 3rd edition (TEMA-3), a standardized math assessment that assesses numbering skills, number-comparison facility, numeral literacy, mastery of number facts, calculation skills, and understanding of concepts (Ginsburg \& Baroody, 2003). The TEMA-3 has been normed for children between the ages of 3 years 0 months and 8 years 11 months. We administered Form B of the TEMA-3, which has demonstrated high reliability, with Cronbach's alpha of 0.96 (Ginsburg \& Baroody, 2003). Raw TEMA-3 scores were used as the measure of children's math abilities.

\subsection{Statistical analyses}

A series of regression models were estimated to examine child and parent factors that related to children's math abilities. First, children's math achievement on the TEMA-3 was regressed on the most distal predictors, i.e., our parent factors, including parents' math scores on the Woodcock- Johnson, home math activities, and parents' level of education as well as children's demographic factors, i.e., age and gender. Child cognitive factors were then hierarchically added to this model. The order of these child-level predictors was determined based on each construct's theoretical relevance to the math outcomes measured here. We first included the domain-general predictors, expressive vocabulary and inhibitory control, followed by ANS acuity, which is 
numerical in nature but does not rely on exact number representations. Finally, SFON tendency was included as the final predictor given that it involves exact numbers. 


\subsection{Results}

\subsection{Preliminary analyses}

Level of education for parents in this sample ranged from a high school degree or equivalent to completed Graduate degree, with $90 \%$ of parents reporting having earned at least a Bachelor's degree. Parents varied considerably in their math scores, as measured by the Woodcock-Johnson. Although the average standardized composite math score was 107.00 (SD = 12.51), scores ranged from 71 to 140 . Reports of math activities in the home ranged from 0.53 to 3.32 , with an average score of $1.76(\mathrm{SD}=0.57)$. For reference, a score of 2 indicated that an activity occurred roughly once per week.

Children's scores on the DVAP ranged from 44 to 182 words known, as reported by parents. Most children produced around 104 words of those listed $(S D=26.71)$. Children's overall scores on the incongruent trials of the Day-Night Stroop task ranged from 0.25 to 2 (with 0 indicating an incorrect response, 1 indicating a self-correction, and 2 indicating a correct response). In the control condition of the Day-Night Stroop task, scores ranged from 0.19 to 2 (again, with 0 indicating an incorrect response, 1 indicating a self-correction, and 2 indicating a correct response). Children were fairly accurate overall on this task, with average scores of $1.40(\mathrm{SD}=0.52)$ and 1.58 $(\mathrm{SD}=0.44)$ on the incongruent and control trials, respectively. Children's performance on the nonsymbolic number comparison task also varied widely from $33 \%$ to $94 \%$ accuracy. On average, children were above chance overall $(\mathrm{M}=64 \%, \mathrm{SD}=14 \%)$ as well as on the correlated, neutral, and anticorrelated trials $(\mathrm{M}=64 \%, \mathrm{SD}=15 \% ; \mathrm{M}=63 \%, \mathrm{SD}=16 \% ; \mathrm{M}=64 \%, \mathrm{SD}=19 \%$, respectively). Furthermore, $79 \%$ of children were above chance (50\%) on the overall task and 
$78 \%, 72 \%$, and $72 \%$ of children were above chance on the correlated, neutral, and anticorrelated trials, respectively. Children's tendency to focus on number in the SFON assessments also varied across tasks. In the "model" task, $53 \%$ of children either recreated the model correctly or verbally referenced number on all three trials, $28 \%$ did so on two trials, and $11 \%$ did so only on one trial. The final $9 \%$ of children never focused on number in this task. Similarly, in the "puppet" task, $62 \%$ of children fed the puppet the same number of marbles or verbally referenced number on all three trials, $17 \%$ did so on two trials, $12 \%$ did so on one trial, and $10 \%$ never focused on number in this task. Children focused on number either through action or verbally on 2.24 trials $(\mathrm{SD}=$ $0.97)$ out of 3 in the "model" task $(\mathrm{M}=2.07, \mathrm{SD}=1.00$ for action and $\mathrm{M}=0.42, \mathrm{SD}=0.82$ verbally) and on 2.30 trials $(\mathrm{SD}=1.02)$ out of 3 in the "puppet" task $(\mathrm{M}=2.05, \mathrm{SD}=1.14$ for action and $\mathrm{M}=0.94, \mathrm{SD}=1.05$ verbally). Finally, performance on the TEMA-3, as measured by raw scores, ranged from 1 to 31 , with an average of $12.41(\mathrm{SD}=5.51)$. Descriptive statistics and correlations for all study variables are shown in Table 1. 
Table 1 Descriptive statistics and correlations for key study variables, $\mathrm{N}=112$

Values shown in the table are Pearson correlations except for associations with parental education, where point-biserial correlations are shown.

$$
{ }^{\dagger} p<.10, * p<.05, * * p<.01, * * * p<.001
$$

\begin{tabular}{|c|c|c|c|c|c|c|c|c|c|c|}
\hline & 1 & 2 & 3 & 4 & 5 & 6 & 7 & 8 & 9 & 10 \\
\hline 1. Parent Math Ability & 1.00 & & & & & & & & & \\
\hline 2. Home Math Activities & -.11 & 1.00 & & & & & & & & \\
\hline 3. Parent Education & $.32 * * *$ & .09 & 1.00 & & & & & & & \\
\hline 4. Child Age (months) & -.15 & -0.07 & -.01 & 1.00 & & & & & & \\
\hline 5. Child Vocabulary & -.06 & $.32 * * *$ & .01 & -.03 & 1.00 & & & & & \\
\hline $\begin{array}{l}\text { 6. Child Inhibitory Control- Incongruent } \\
\text { Condition }\end{array}$ & .12 & .02 & .11 & .01 & .04 & 1.00 & & & & \\
\hline $\begin{array}{l}\text { 7. Child Inhibitory Control- Control } \\
\text { Condition }\end{array}$ & -.06 & -.10 & .02 & -.11 & -.07 & $.36 * * *$ & 1.00 & & & \\
\hline 8. Child ANS Acuity & $.18^{\dagger}$ & .05 & $.20 *$ & .02 & $.30 * *$ & $.42 * * *$ & $.16^{\dagger}$ & 1.00 & & \\
\hline 9. Child SFON & .04 & .15 & .10 & .10 & .06 & $.16^{\dagger}$ & .004 & $.24 *$ & 1.00 & \\
\hline 10. Child Math Ability & .14 & $.19 *$ & .12 & -.01 & -.002 & $.40 * * *$ & $.21 *$ & $.43 * * *$ & $.32 * * *$ & 1.00 \\
\hline$M$ & 107.00 & 1.76 & 0.90 & 48.97 & 104.00 & 1.40 & 1.58 & 0.64 & 4.54 & 12.41 \\
\hline$S D$ & 12.51 & 0.57 & 0.30 & 0.92 & 26.71 & 0.52 & 0.44 & 0.14 & 1.54 & 5.51 \\
\hline
\end{tabular}




\subsection{Parent predictors of children's math abilities}

Children's raw scores on the TEMA-3 were first regressed on parents' composite math score from the Woodcock-Johnson, home math activities, parents' education (with less than a Bachelor's degree as the reference group), child's age, and child's gender (with female as the reference group). This model was not significant overall, $F(5,106)=1.51, p=.194$, and explained $2 \%$ of the variance in children's math abilities based on the adjusted $R^{2}$. Results from this model are shown in the first column of Table 2. Importantly, parents who reported engaging in math activities in the home more frequently tended to have children with more advanced math abilities, $p=.040$, unstandardized $\mathrm{B}=1.94, \mathrm{CI}=[0.09,3.79]$. Specifically, a 1 SD increase in math activities at home was associated with a 0.21 SD increase in children's math abilities above and beyond the effects of parent math ability, level of education, and child age and gender. Parent math ability, level of education, child gender, and child age were unrelated to children's math abilities.

\subsection{Child predictors of children's math abilities}

Child characteristics were then sequentially added to this regression model. First, children's expressive vocabulary was added to the model. This resulted in a non-significant increase in explained variance, $\Delta F(1,105)=0.35, p=.558$, as well as a non-significant overall model, $F(6,105)=1.31, p=.261$. As shown in the second column of Table 2 , children's vocabulary scores were not related to math skills.

Next, performance on the incongruent and control conditions of the Day-Night Stroop task was added to the model. The inclusion of these variables resulted in a significant increase in 
explained variance, $\Delta F(2,103)=9.96, p<.001$. This model was significant overall, adjusted $R^{2}=$ $.16, F(8,103)=3.64, p<.001$. As shown in the second column of Table 2 , inhibitory control was significantly associated with children's math abilities, $p=.001$, unstandardized $\mathrm{B}=3.68, \mathrm{CI}=$ $[1.62,5.75]$, as a $1 \mathrm{SD}$ increase in accuracy on the incongruent condition of the Day-Night Stroop was associated with a $0.35 \mathrm{SD}$ increase in math scores, above and beyond the effects of other covariates.

ANS acuity was then added as a predictor to this model, $\Delta F(1,102)=13.50, p<.0001$. This model was also significant overall, $F(9,102)=5.13, p<.001$, explained $25 \%$ of the variance in math skills according to the adjusted $R^{2}$ value, and is shown in the third column of Table 2 . Even when controlling for parent factors and children's vocabulary and inhibitory control, child ANS acuity was significantly related to math scores, $p<.0001$, unstandardized $\mathrm{B}=14.56, \mathrm{CI}=$ $[6.70,22.42]$. A 1 SD increase in accuracy on the ANS task was associated with a 0.36 SD increase in math scores, above and beyond the effects of other variables.

Finally, SFON tendency was added as a predictor of children's math abilities. This model was significant overall, $F(10,101)=5.37, p<.001$, and explained $28 \%$ of the variance according to the adjusted $R^{2}$. This model also explained additional variance in children's math abilities compared to the model that did not include SFON tendency, $\Delta F(1,101)=5.55, p=.020$. In this model, SFON tendency was a significant predictor of math abilities, $p=.020$, unstandardized $\mathrm{B}=$ $0.72, \mathrm{CI}=[0.11,1.33]$, as a $1 \mathrm{SD}$ increase in SFON tendency was associated with a $0.20 \mathrm{SD}$ increase in scores on the TEMA-3, above and beyond the effects of other variables. Additionally, ANS acuity, inhibitory control and parent math activities remained significant predictors even with the inclusion of SFON tendency in this model, with standardized coefficients of $0.32,0.21$, and 0.21 respectively. Results from this model are shown in the final column of Table 2. 


\section{Table 2 Parent and child factors as predictors of children's math ability}

$R^{2}$ values shown in the Table differ from those presented in the test as the Table displays unadjusted $R^{2}$ values and the text displays adjusted $R^{2}$ values.

$$
{ }^{\dagger} p<.10, * p<.05, * * p<.01, * * * p<.001
$$

\begin{tabular}{|c|c|c|c|c|c|}
\hline & $b(S . E)$. & $b(S . E)$. & $b(S . E)$. & $b(S . E)$. & $b(S . E)$. \\
\hline Parent Math Ability & $0.06(0.04)$ & $0.06(0.04)$ & $0.05(0.04)$ & $0.03(0.04)$ & $0.03(0.04)$ \\
\hline Home Math Activities & $1.94 *(0.93)$ & $2.12 *(0.98)$ & $2.20 *(0.92)$ & $2.35 * *(0.87)$ & $2.04 *(0.86)$ \\
\hline Parent Bachelor's Degree & $1.17(1.85)$ & $1.15(1.86)$ & $0.36(1.72)$ & $-0.44(1.64)$ & $-0.61(1.61)$ \\
\hline Child Age in Months & $0.18(0.57)$ & $0.18(0.57)$ & $0.21(0.54)$ & $0.10(0.51)$ & $-0.03(0.50)$ \\
\hline Child is Male & $-0.57(1.03)$ & $-0.51(1.04)$ & $0.60(0.99)$ & $0.62(0.94)$ & $0.95(0.93)$ \\
\hline Child Vocabulary & & $-0.01(0.02)$ & $-0.02(0.02)$ & $-0.04(0.02)$ & $-0.04 \div(0.02)$ \\
\hline Child Inhibitory & & & $3.68 * *(1.04)$ & $2.33 *(1.05)$ & $2.23 *(1.03)$ \\
\hline $\begin{array}{l}\text { Control- Incongruent } \\
\text { Condition }\end{array}$ & & & & & \\
\hline $\begin{array}{l}\text { Child Inhibitory Control- } \\
\text { Control Condition }\end{array}$ & & & $1.48(1.20)$ & $1.21(1.14)$ & $1.32(1.12)$ \\
\hline Child ANS Acuity & & & & $14.56 * * *(3.96)$ & $12.85 * *(3.94)$ \\
\hline Child SFON & & & & & $0.72 *(0.31)$ \\
\hline Constant & $-7.32(29.28)$ & $-6.19(29.43)$ & $-13.95(28.00)$ & $-10.42(26.46)$ & $-5.91(25.96)$ \\
\hline$R^{2}$ & .07 & .07 & .22 & .31 & .35 \\
\hline$\Delta R^{2}$ & - & .003 & $.15^{* * *}$ & $.09^{* * *}$ & $.04^{*}$ \\
\hline
\end{tabular}




\subsection{Discussion}

The goals of the present study were to examine parent and child predictors of children's math achievement and to investigate the unique contributions of each of these factors. We found that the frequency of home numeracy activities, children's own inhibitory control, approximate number system acuity, and spontaneous focusing on number each provided independent contributions to math achievement in early childhood.

\subsection{Parent-level predictors of children's math performance}

We found that the frequency with which parents reported engaging in math activities with their children was positively related to their children's math performance. This finding adds to a growing literature documenting the role of the home numeracy environment in children's math development. However, some other studies have not replicated this link between math activity frequency and children's math performance (see Elliott \& Bachman, 2018, for a review). Thus, it remains critical to continue to develop more sensitive measures of the home numeracy environment to understand the role that math activities play in children's development. Specifically, work that continues to examine the benefits children gain from engaging in particular types of math activities or particular types of interactions with their parents during those activities may help to elucidate the role of home numeracy.

Interestingly, the frequency of home math activities was the only significant parent-level predictor of children's performance in this study. In contrast to previous work, here we found no 
effect of parent education on children's math performance. It is important to note, however, that there was limited variability in our sample as most parents participating in this study had completed college. It may be that this relatively homogeneous sample did not have enough variability in parental education to detect differences based on parent education. Similarly, we also did not replicate previous findings that parental math ability predicts children's math ability (Braham \& Libertus, 2017; Hart et al., 2009). These associations failed to reach conventional significance levels in controlled regression models as well as at the bivariate level. One possible explanation for this finding is the relatively young age of the children in our study compared to past work, as the foundational math skills learned during the preschool years may be less related to parents' own math achievement. Another possible explanation is that we measured two qualitatively different sets of math skills in children and adults. The Woodcock- Johnson Math Calculation subtest taps into parents' ability to do calculus or other more advanced math, which may be highly dependent on parents' overall education level or how well they remember the procedures to solve such problems, and the Math Fluency subtest depends heavily on fact retrieval. In contrast, the Test of Early Mathematics Ability requires children to count, identify Arabic numerals, and solve simple word problems. The differences in which aspects of math we measured in parents and children respectively could account for the null results, regardless of whether generational associations are attributable to genetic or environmental links.

If these associations are due to variability in the environment, parental math ability may also be less predictive of children's math skills in early childhood if parents' abilities to teach their children math and engage in math activities do not hinge upon their own math skills. In other words, parents' own proficiency in math is likely less critical for playing a board game or teaching a child to count during preschool than helping with homework in elementary or middle school. In 
contrast, it is less clear why these links between parents' and children's math skills would be lower in this study if these associations are attributable to genetic influences. Although very few studies have examined heritability of math in particular, some work does indicate that heritability estimates of domain-general cognitive abilities such as IQ increase as children get older (Bouchard, 2013). As such, it is possible that environmental influences are stronger in early childhood. Unfortunately, in the absence of a more complex behavioral genetic design, disentangling these explanations in our sample is not possible.

\subsection{Child-level predictors of children's math performance}

Critically, we found that children's inhibitory control, ANS acuity, and SFON tendency were all independently related to their math achievement, even when controlling for parent factors, demo- graphic factors, and children's expressive vocabulary. These results add to the considerable literature documenting the consistent relations between inhibitory control and math ability (Allan et al., 2014; Aunio et al., 2004; St Clair-Thompson \& Gathercole, 2006; Clark et al., 2010; Fuhs \& McNeil, 2013), as well as between ANS acuity and math ability even when controlling for a host of domain-general and domain-specific cognitive abilities (Bonny \& Lourenco, 2013; Libertus et al., 2013b, 2013a; Keller \& Libertus, 2015; Mazzocco et al., 2011). This further extends past work from Batchelor et al. (2015), who found that SFON predicted children's math performance above and beyond children's working memory. We add to this literature by demonstrating that associations between SFON tendency and math skills cannot be explained by children's other cognitive abilities like inhibitory control or ANS acuity, nor by parent or contextual factors, consistent with recent work demonstrating that children's SFON is not related 
to home math activities (Rathé et al., 2020). Here, we find that the child-level factors SFON, ANS, and inhibitory control each explain a unique portion of children's math. Despite some conceptual similarities between these cognitive abilities, they each appear to play a unique role in the development of early math skills.

Furthermore, these child-level predictors accounted for considerably more variance in children's math performance than the parent-level predictors. This suggests that while parenting factors may be important, children's own propensities should not be ignored. Additionally, it is critical to examine how parent factors may shape child factors to predict children's math performance. For example, future work examining how parental factors predict children's skills, and how children's skills perhaps shape parental engagement in math activities, is warranted. Examining the potential for bidirectional relations between parent-level factors, child-level factors, and children's math achievement may provide useful insight. Similarly, future work may investigate whether these parent and child factors interact to predict children's math performance such that some children may benefit more from parent engagement than others, perhaps based on their own cognitive abilities, to fully understand the roles of each of these factors. Nonetheless, this work suggests that both parent engagement and children's cognitive abilities are related to children's performance.

However, several important questions regarding the nature of the associations between specific child cognitive factors and math remain unanswered, especially when considering the unique associations seen for each of the constructs included here. For example, our results contradict past claims that the link between the ANS and math may be explained by individual variations in inhibitory control or SFON (e.g., Fuhs \& McNeil, 2013; Fuhs et al., 2018). If ANS acuity does in fact predict math skills when controlling for these hypothesized mechanisms, 
alternative explanations for how this non-symbolic number sense relates to symbolic math skills are needed (see Feigenson et al., 2013, for possible mechanisms). Similarly, more work is needed to understand how spontaneous attention to numerical information predicts math skills even when accounting for children's inhibitory control and whether these associations persist when controlling for factors such as attention and cognitive flexibility.

\subsection{Limitations, conclusions, and future directions}

In the current study, we examined the unique contributions of the well-documented associations between parents' education, math skills and math activities, children's domaingeneral and domain- specific cognitive skills, and children's math achievement in early childhood. We found that parent math activities in addition to children's inhibitory control, ANS acuity, and SFON tendency uniquely predicted children's math skills over and above the other factors. As such, we replicate and extend past work by demonstrating that math activities at home, inhibitory control, the ANS, and SFON are important constructs for future study as predictors of math and potential targets for interventions designed to improve math abilities.

Several limitations of this study warrant discussion. As noted above, more nuanced measures of children's math-related experiences at home would shed further light on the nature of the association between these predictors and children's math performance. In addition, the data in the present study were correlational and collected from a single time point; as such, the direction and causal nature of these associations remains unclear. Finally, our sample consisted primarily of highly educated, White mothers and their children in the United States limiting our ability to generalize our findings to a broader population. 
Despite these limitations, we find that child and parent factors play a unique role in explaining variability in preschool-aged children's math abilities above and beyond the significant influences of the other factors. However, many important questions regarding the development of children's math abilities remain, including understanding how these factors may interact to shape children's development. In particular, future work may explore how child-level factors are shaped by parents' provision of math activities or how these factors moderate the effect of parents' engagement in math activities. It is possible that some children may benefit more from math activities than others, perhaps due to stronger vocabulary, inhibitory control, ANS acuity, or SFON tendency. In addition, it is possible that parents tailor the frequency and types of math activities they provide to their children's domain-general and domain-specific cognitive skills. Understanding the mechanisms for each of these effects will undoubtedly prove useful. Finally, given that these factors appear to operate independently to influence children's math performance, future work may continue to examine the impact of interventions designed to improve or increase one of these factors and the consequences of this for children's math achievement. 


\section{Bibliography}

Agarwal, S., \& Mazumder, B. (2013). Cognitive abilities and household financial decision making. American Economic Journal: Applied Economics, 5(1), 193-207. https://doi.org/10.1257/app.5.1.193

Allan, N. P., Hume, L. E., Allan, D. M., Farrington, A. L., \& Lonigan, C. J. (2014). Relations between inhibitory control and the development of academic skills in preschool and kindergarten: A meta-analysis. Developmental Psychology, 50 (10), 2368-2379. https://doi.org/10.1037/a0037493

Aunio, P., Ee, J., Lim, S. E. A., Hautamäki, J., \& Van Luit, J. (2004). Young children's number sense in Finland, Hong Kong and Singapore. International Journal of Early Years Education, 12(3), 195-216. https://doi.org/10.1080/ 0966976042000268681

Batchelor, S., Inglis, M., \& Gilmore, C. K. (2015). Spontaneous focusing on numerosity and the arithmetic advantage. Learning and Instruction, 40, 79-88. https://doi.org/10.1016/j.learninstruc.2015.09.005

Blevins-Knabe, B., \& Musun-Miller, L. (1996). Number use at home by children and their parents and its relationship to early mathematical performance. Early Development \& Parenting, 5(1), 35-45. https://doi.org/10.1002/(SICI)1099- 0917(199603)5:1<35::AIDEDP113>3.0.CO;2-0

Bonny, J., \& Lourenco, S. (2013). The approximate number system and its relation to early math achievement : Evidence from the preschool years. Journal of Experimental Child Psychology, 114(3), 375-388. https://doi.org/10.1016/j.jecp. 2012.09.015

Bouchard, T. J. (2013). The Wilson effect: The increase in heritability of IQ with age. Twin Research and Human Genetics : The Official Journal of the International Society for Twin Studies, 16(5), 923-930. 10.1017/thg.2013.54

Braham, E. J., \& Libertus, M. E. (2017). Intergenerational associations in numerical approximation and mathematical abilities. Developmental Science, 20(5), e12436. https://doi.org/10.1111/desc.12436

Clark, C. A. C., Pritchard, V. E., \& Woodward, L. J. (2010). Preschool executive functioning abilities predict early mathematics achievement. Developmental Psychology, 46(5), 11761191. https://doi.org/10.1037/a0019672

Coubart, A., Izard, V., Spelke, E. S., Marie, J., \& Streri, A. (2014). Dissociation between small and large numerosities in newborn infants. Developmental Science, 17(1), 11-22. https://doi.org/10.1111/desc. 12108 
Crane, J. (1996). Effects of home environment, SES, and maternal test scores on mathematics achievement. The Journal of Educational Research, 89(5), 305-314.

Currie, J., \& Thomas, D. (1999). Early test scores, socioeconomic status and future outcomes. NBER Working Papers. https://doi.org/10.3386/w6943

Davis-Kean, P. E. (2005). The influence of parent education and family income on child achievement: The indirect role of parental expectations and the home environment. Journal of Family Psychology, 19(2), 294-304. https://doi.org/10. 1037/0893-3200.19.2.294

De Smedt, B., \& Gilmore, C. K. (2011). Defective number module or impaired access? Numerical magnitude processing in first graders with mathematical difficulties. Journal of Experimental Child Psychology, 108(2), 278-292. https://doi. org/10.1016/j.jecp.2010.09.003

Dehaene, S. (1997). The number sense: How mathematical knowledge is embedded in our brains. Oxford University Press.

Dietrich, J. F., Huber, S., \& Nuerk, H.-C. (2015). Methodological aspects to be considered when measuring the approximate number system (ANS): a research review. Frontiers in Psychology, 6. https://doi.org/10.3389/fpsyg. 2015.00295

Duncan, G. J., \& Magnuson, K. (2011). The nature and impact of early achievement skills, attention skills, and behavior problems. In G. J. Duncan \& R. J. Murnane (Eds.), Whither opportunity?: Rising inequality, schools and children's life chances (pp. 47-70). Russell Sage Foundation.

Duncan, G. J., Magnuson, K., \& Votruba-Drzal, E. (2014). Boosting family income to promote child development. The Future Of Children, 24(1), 99-120. https://doi.org/10.1353/foc.2014.0008

Elliott, L., \& Bachman, H. J. (2018). How do parents foster young children's math skills?. Child Development Perspectives, 12(1), 16-21.

Feigenson, L., Libertus, M. E., \& Halberda, J. (2013). Links between the intuitive sense of number and formal mathematics ability. Child Development Perspectives, 7(2), 74-79. https://doi.org/10.1111/cdep.12019

Foster, E. M. (2002). How economists think about family resources and child development. Child Development, 73(6), 1904-1914. https://doi.org/10.1111/1467-8624.00513

Fuhs, M. W., \& McNeil, N. (2013). ANS acuity and mathematics ability in preschoolers from lowincome homes : Contributions of inhibitory control. Developmental Science, 1(1), 136148. https://doi.org/10.1111/desc.12013

Fuhs, M. W., Nesbitt, K. T., \& O'Rear, C. D. (2018). Approximate number system task performance: Associations with domain-general and domain-specific cognitive skills in 
young children. Journal of Numerical Cognition, 4(3), 590-612. https://doi.org/10.5964/jnc.v4i3.141

Gebuis, T., Cohen Kadosh, R., \& Gevers, W. (2016). Sensory-integration system rather than approximate number system underlies numerosity processing: A critical review. Acta psychologica, 171, 17-35. https://doi.org/10.1016/j.actpsy. 2016.09.003

Gerstadt, C. L., Hong, Y. J., \& Diamond, A. (1994). The relationship between cognition and action: Performance of children 312-7 years old on a stroop-like day-night test. Cognition, 53(2), 129-153. https://doi.org/10.1016/0010- 0277(94)90068-X

Gilmore, C. K., Attridge, N., Clayton, S., Cragg, L., Johnson, S., Marlow, N., Inglis, M., \& Simms, V. (2013). Individual differences in inhibitory control, not non-verbal number acuity, correlate with mathematics achievement. PloS One, 8 (6), e67374. https://doi.org/10.1371/journal.pone.0067374

Gilmore, C. K., Attridge, N., \& Inglis, M. (2011). Measuring the approximate number system. Quarterly Journal of Experimental Psychology, 64(11), 2099-2109. https://doi.org/10.1080/17470218.2011.574710

Ginsburg, H. P., \& Baroody, A. J. (2003). Test of early math ability. PRO-ED.

Gray, S. A., \& Reeve, R. A. (2016). Number-specific and general cognitive markers of preschoolers' math ability profiles. Journal of Experimental Child Psychology, 147, 1-21. https://doi.org/10.1016/j.jecp.2016.02.004

Halberda, J., Mazzocco, M. M. M., \& Feigenson, L. (2008). Individual differences in non-verbal number acuity correlate with maths achievement. Nature, 455(7213), 665-668. https://doi.org/10.1038/nature07246

Hannula, M. M., \& Lehtinen, E. (2005). Spontaneous focusing on numerosity and mathematical skills of young children. Learning and Instruction, 15(3), 237-256. https://doi.org/10.1016/j.learninstruc.2005.04.005

Hannula, M. M., Lepola, J., \& Lehtinen, E. (2010). Spontaneous focusing on numerosity as a domain-specific predictor of arithmetical skills. Journal of Experimental Child Psychology, 107(4), 394-406. https://doi.org/10.1016/j.jecp.2010.06. 004

Hannula-Sormunen, M. M., Lehtinen, E., \& Räsänen, P. (2015). Preschool children's spontaneous focusing on numerosity, subitizing, and counting skills as predictors of their mathematical performance seven years later at school. Mathematical Thinking and Learning, 17(2-3), 155-177. https://doi.org/10.1080/10986065.2015.1016814

Hart, S. A., Petrill, S. A., Thompson, L. A., \& Plomin, R. (2009). The ABCs of math: A genetic analysis of mathematics and its links with reading ability and general cognitive ability. Journal of Educational Psychology, 101(2), 388-402. https://doi.org/10.1037/a0015115 
Huntsinger, C. S., Jose, P. E., \& Luo, Z. (2016). Parental facilitation of early mathematics and reading skills and knowledge through encouragement of home-based activities. Early Childhood Research Quarterly, 37, 1-15. https://doi.org/10.1016/j.ecresq.2016.02.005

Jordan, N. C., Kaplan, D., Ramineni, C., \& Locuniak, M. N. (2009). Early math matters: Kindergarten number competence and later mathematics outcomes. Developmental Psychology, 45(3), 850-867. https://doi.org/10.1037/a0014939

Jordan, N. C., \& Levine, S. C. (2009). Socioeconomic variation, number competence, and mathematics learning difficulties in young children. Developmental Disabilities Research Reviews, 15(1), 60-68. https://doi.org/10.1002/ddrr.46

Keller, L., \& Libertus, M. (2015). Inhibitory control may not explain the link between approximation and math abilities in kindergarteners from middle class families. Frontiers in Psychology, 6, 685. https://doi.org/10.3389/fpsyg.2015.00685

LeFevre, J.-A., Skwarchuk, S. L., Smith-Chant, B. L., Fast, L., Kamawar, D., \& Bisanz, J. (2009). Home numeracy experiences and children's math performance in the early school years. Canadian Journal of Behavioural Science/ Revue Canadienne Des Sciences Du Comportement, 41(2), 55. https://doi.org/10.1037/a0014532

Leibovich, T., \& Ansari, D. (2016). The symbol-grounding problem in numerical cognition: A review of theory, evidence, and outstanding questions. Canadian Journal of Experimental Psychology/Revue Canadienne De Psychologie Expérimentale, 70(1), 12-23. https://doi.org/10.1037/cep0000070

Leibovich, T., Katzin, N., Harel, M., \& Henik, A. (2017). From "sense of number" to "sense of magnitude": The role of continuous magnitudes in numerical cognition. Behavioral and Brain Sciences, 40, e164. https://doi.org/10.1017/ S0140525X16000960

Lepola, J., \& Hannula-Sormunen, M. (2019). Spontaneous focusing on numerosity and motivational orientations as predictors of arithmetical skills from kindergarten to grade 2. Educational Studies in Mathematics, 100(3), 251-269. https://doi.org/10.1007/s10649018-9851-2

Levine, S. C., Suriyakham, L. W., Rowe, M. L., Huttenlocher, J., \& Gunderson, E. A. (2010). What counts in the development of young children's number knowledge? Developmental Psychology, 46(5), 1309-1319. https://doi.org/ 10.1037/a0019671

Libertus, M. E., \& Brannon, E. (2009). Behavioral and Neural Basis of Number Sense in Infancy. Current Directions in Psychological . . ., 18(6), 1457-1465. https://doi.org/10.1111/j.14678721.2009.01665.x.Behavioral

Libertus, M. E., Feigenson, L., \& Halberda, J. (2013a). Is approximate number precision a stable predictor of math ability? Learning and Individual Differences, 25, 126-133. https://doi.org/10.1016/j.lindif.2013.02.001 
Libertus, M. E., Feigenson, L., \& Halberda, J. (2013b). Numerical approximation abilities correlate with and predict informal but not formal mathematics abilities. Journal of Experimental Child Psychology, 116(4), 829-838. https://doi. org/10.1016/j.jecp.2013.08.003

Libertus, M. E., Odic, D., Feigenson, L., \& Halberda, J. (2015). A Developmental Vocabulary Assessment for Parents (DVAP): Validating parental report of vocabulary size in 2- to 7year-old children. Journal of Cognition and Development, 16(3), 442-454. https://doi.org/10.1080/15248372.2013.835312

Mazzocco, M. M. M., Feigenson, L., \& Halberda, J. (2011). Preschoolers' precision of the approximate number system predicts later school mathematics performance. PloS One, 6(9), e23749. https://doi.org/10.1371/journal.pone.0023749 McMullen, J., HannulaSormunen, M. M., \& Lehtinen, E. (2015). Preschool spontaneous focusing on numerosity predicts rational number conceptual knowledge 6 years later. ZDM, 47(5), 813-824. https://doi.org/10.1007/s11858-015-0669-4

Montgomery, D. E., \& Koeltzow, T. E. (2010). A review of the day-night task: The Stroop paradigm and interference control in young children. Developmental Review, 30(3), 308330. https://doi.org/10.1016/j.dr.2010.07.001

Mutaf Yildiz, B., Sasanguie, D., De Smedt, B., \& Reynvoet, B. (2018). Investigating the relationship between two home numeracy measures: A questionnaire and observations during Lego building and book reading. British Journal of Developmental Psychology, 36(2), 354-370. https://doi.org/10.1111/bjdp.12235

Nanu, C. E., McMullen, J., Munck, P., \& Hannula-Sormunen, M. M. (2018). Spontaneous focusing on numerosity in preschool as a predictor of mathematical skills and knowledge in the fifth grade. Journal of Experimental Child Psychology, 169, 42-58. https://doi.org/10.1016/j.jecp.2017.12.011

Purpura, D. J., Hume, L. E., Sims, D. M., \& Lonigan, C. J. (2011). Early literacy and early numeracy: The value of including early literacy skills in the prediction of numeracy development. Journal of Experimental Child Psychology, 110(4), 647-658. https://doi.org/10.1016/j.jecp.2011.07.004

Rathé, S., Torbeyns, J., De Smedt, B., \& Verschaffel, L. (2020). Are children's spontaneous number focusing tendencies related to their home numeracy environment? ZDM, 52(4), 729-742. https://doi.org/10.1007/s11858-020-01127-z

Reyna, V. F., \& Brainerd, C. J. (2007). The importance of mathematics in health and human judgment: Numeracy, risk communication, and medical decision making. Learning and Individual Differences, 17(2), 147-159. https://doi.org/10.1016/j.lindif.2007.03.010

Soltész, F., Szücs, D., \& Szücs, L. (2010). Relationships between magnitude representation, counting and memory in 4- to 7-year-old children: A developmental study. Behavioral and Brain Functions, 6(1), 13. https://doi.org/10.1186/1744-9081-6-13 
St Clair-Thompson, H. L., \& Gathercole, S. E. (2006). Executive functions and achievements in school: Shifting, updating, inhibition, and working memory. Quarterly Journal of Experimental Psychology, 59(4), 745-759. https:// doi.org/10.1080/17470210500162854

Starr, A., Libertus, M. E., \& Brannon, E. M. (2013). Number sense in infancy predicts mathematical abilities in childhood. Proceedings of the National Academy of Sciences of the United States of America, 110(45), 18116-18120. https://doi.org/10.1073/pnas.1302751110

Trusty, J., Robinson, C. R., Plata, M., \& Ng, K.-M. (2000). Effects of gender, socioeconomic status, and early academic performance on postsecondary educational choice. Journal of Counseling \& Development, 78(4), 463-472. https://doi. org/10.1002/j.15566676.2000.tb01930.x

Woodcock, R. W., McGrew, K. S., \& Mather, N. (2001). Woodcock-Johnson Tests of Achievement (Vol. 3). Riverside Publishing. https://doi.org/10.2307/302397 